\title{
Flow-Injection Extraction-Spectrophotometric Determination of Copper with Dithiocarbamates
}

\author{
Joanna SzPUnAR-KobińSKa and Marek Trojanowicz \\ Department of Chemistry, University of Warsaw, Pasteura 1, 02-093 Warsaw, Poland
}

\begin{abstract}
Several salts of $N, N$-substituted derivatives of dithiocarbamic acid were studied as potential reagents for flow-injection extraction-spectrophotometric determination of copper. A specific and sensitive method for the determination of copper was developed. Copper is extracted with a chloroform solution of lead diethyldithiocarbamate (DDTC) and the absorbance of the $\mathrm{Cu}$-DDTC complex is measured at $436 \mathrm{~nm}$. Effects of total flow rate, sample volume, mixing and extraction coils length are studied. The detection limit is $0.04 \mathrm{ppm}$ of $\mathrm{Cu}$ and calibration graph is linear up to $2 \mathrm{ppm} \mathrm{Cu}$. The method developed was applied to the determination of copper in samples of water and plant materials showing good precision and accuracy.
\end{abstract}

Keywords Flow injection analysis, extraction, dithiocarbamic acid derivatives, copper, natural water, plant material

$N, N$-Substituted derivatives of dithiocarbamic acid and their various salts are widely used as reagents for the spectrophotometric determination of copper. ${ }^{1,2}$ The reagent coordinates with copper through the two sulfur atoms to form a water-insoluble chelate with a four member ring. The spectrophotometric determination can be carried out in the aqueous phase after stabilization of the pseudo-solution with a protective colloid ${ }^{1}$ but higher sensitivity and better accuracy are attained after extracting the corresponding copperdithiocarbamate into organic solvents, especially chloroform or carbon tetrachloride.

Flow injection analysis (FIA) has recently been widely applied both to research and to routine chemical determinations owing to the high sample throughput, relatively low cost and kinetic elimination of interferences due to the short interaction time of the analyte with the reagent.

Several papers on the flow injection determination of copper using various detection techniques have already been reported. They include atomic absorption spectrometry ${ }^{3,4}$, potentiometry ${ }^{5,6}$, chemiluminescence ${ }^{7,8}$, spectrophotometry ${ }^{9-13}$ and kinetic measurements. ${ }^{9,14,15}$

The spectrophotometric methods published usually involve sophisticated reagents, suffer from interferences with other metals which must first be removed and have relatively high determination limits and a narrow range of linearity. ${ }^{10,11}$

Extraction performed in a flow-injection system can be considered as a convenient method for decreasing the determination limit and increasing the selectivity of the analytical methods. ${ }^{16}$

The purpose of this work has been to study the possibility of applying dithiocarbamates as reagents for the extraction-spectrophotometric determination of copper in a flow injection system. A sensitive and selective method for the determination of copper in natural waters and plant materials with lead diethyldithiocarbamate has been developed. Hitherto, zincdiethyldithiocarbamate has been used for extractionpreconcentration of copper in a closed-loop system. ${ }^{17}$

\section{Experimental}

\section{Reagents}

A stock standard copper(II) solution was prepared by dissolving $3.928 \mathrm{~g}$ of cupric sulfate pentahydrate, $\mathrm{CuSO}_{4}$. $5 \mathrm{H}_{2} \mathrm{O}$, in water containing $1 \mathrm{ml}$ of concd. $\mathrm{H}_{2} \mathrm{SO}_{4}$, and diluting the solution with water to 11 . The working solutions were prepared by dilution of the stock solution with water. A $0.4 \mathrm{M}$ ammonia buffer was prepared by dissolving the appropriate amount of ammonium chloride in water and adjusting the $\mathrm{pH}$ to 8.5 with aqueous ammonia. When the carbamate was dissolved in the buffer, $\mathrm{pH}$ of the latter was adjusted after the dissolution of the salt.

Sodium dimethyldithiocarbamate (Na-DMTC) (Fluka), sodium diethyldithiocarbamate (Na-DDTC) (POCh Gliwice, Poland), Sodium pyrrolidinedithiocarbamate (Na-PyDTC) (Hopkin \& Williams, England) and sodium diphenyldithiocarbamate (Na-DPTC) (POCh Gliwice) were used as $0.05 \%(w / v)$ solution in ammonia buffer.

Lead diethyldithiocarbamate (Pb-DDTC) was synthesized by a conventional method from Na-DDTC and $\mathrm{Pb}\left(\mathrm{NO}_{3}\right)_{2}$ and recrystallized before use. Pb-DDTC, zinc diethyldithiocarbamate (Zn-DDTC) (POCh Gliwice) 
and silver diethyldithiocarbamate (Ag-DDTC) (AustranalPraparate, Austria) were used as $0.05 \%(\mathrm{w} / \mathrm{v})$ solutions in $\mathrm{CHCl}_{3}$.

The standard solutions for metal ions interference studies were prepared according to Marczenko. ${ }^{1}$

All other reagents used were of analytical reagent grade. Triple distilled water was used throughout.

\section{Apparatus}

The diagram of the flow injection system for the extraction-spectrophotometric determination of copper is shown in Fig. 1. The system consisted of a DP2-2 Peristaltic pump (MLW Labortechnik, GDR) fitted with acid resistant pump tubes (Sterilin Instruments, England) for the organic phase and Tygon tubes for the aqueous solutions, a home-made injection valve with an exchangeable sample loop, a Teflon segmentor and a membrane phase separator constructed according to Backstrom et al. ${ }^{18} \mathrm{~A}$ Teflon membrane of $0.45 \mu \mathrm{m}$ pore size (Gelman) was used. The flow system was assembled of $0.5 \mathrm{~mm}$ i.d. Teflon tubings and connectors. A Spekol Spectrophotometer (Carl Zeiss, Jena) with a flow cell $(10 \mu \mathrm{l}$ volume, light path $10 \mathrm{~mm})$ equipped with a digital read-out unit PFS-10 (Kortex, Poland) and a strip chart recorder (Laboratorni Pristroje, Czechoslovakia) were jointly used to record the absorbance signal.

pH was measured with a OP-265 pH meter (Radelkis, Hungary).

All the experiments were carried out at $23 \pm 2^{\circ} \mathrm{C}$ in the thermostated laboratory room.

\section{Procedure}

Sample preparation. River water was analyzed without any sample pretreatment. Plant materials were dryashed at $550^{\circ} \mathrm{C}$ during $24 \mathrm{~h}$. The residue was evaporated twice to dryness with concd. hydrofluoric acid, once with concd. hydrochloric acid, dissolved in $1 \mathrm{ml}$ of $1 \mathrm{M} \mathrm{HCl}$, transferred to a $25 \mathrm{ml}$ standard flask and made up with water.

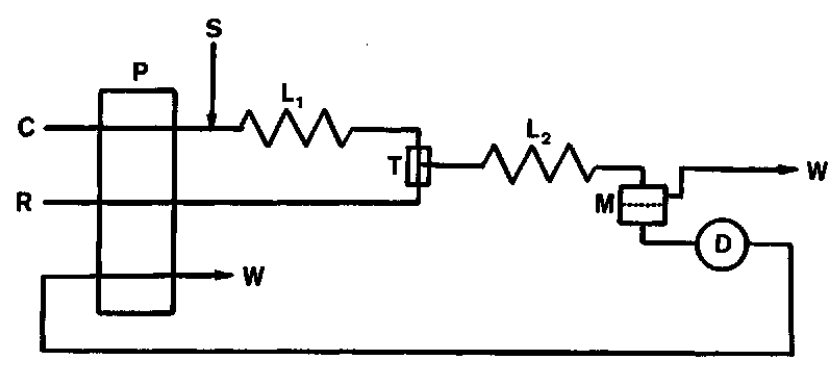

Fig. 1 Flow-injection system for the extraction-spectrophotometric determination of copper. $\mathrm{C}$, carrier solution (ammonia buffer, $\mathrm{pH} 8.5$ ): $\mathrm{R}$, reagent solution $(0.05 \% \mathrm{~Pb}$ DDTC in chloroform); $\mathrm{P}$, peristaltic pump; $\mathrm{S}$, injection point; $\mathrm{L}_{1}$, mixing coil; $\mathbf{L}_{2}$, extraction coil; $\mathrm{T}, \mathrm{T}$-segmentor; $M$, membrane phase separator; $D$, photometer $(\lambda=436 \mathrm{~nm})$; W, waste.
Determination of copper. A $300 \mu$ l aliquot of the sample solution was injected into the carrier stream by a loop-valve injector and then mixed in a mixing coil (100 cm long, $0.5 \mathrm{~mm}$ i.d.). The carrier solution (C) (0.4 M ammonia buffer; $\mathrm{pH} \mathrm{8.5)}$ and the reagent solution ( $\mathrm{R})\left(0.05 \% \mathrm{~Pb}\right.$-DDTC in $\left.\mathrm{CHCl}_{3}\right)$ were pumped into the analytical line with a peristaltic pump at flow rates of 1.5 and $0.5 \mathrm{ml} / \mathrm{min}$, respectively. The streams merged in a Teflon T-segmentor ( $T$ ) where the segmentation process took place. The heterophase color forming reaction was conducted in the extraction coil ( $400 \mathrm{~cm}$ long, $0.5 \mathrm{~mm}$ i.d.), whereupon the phases were separated on the Teflon membrane in the separator (M). The absorbance of the organic phase was monitored at $436 \mathrm{~nm}$. For calibration, a series of copper standard solutions was injected to produce a calibration graph.

\section{Results and Discussion}

\section{Optimization of the flow injection system}

Experiments have shown that adapting of chemical parameters already optimized in many publications (i.e. $\mathrm{pH} 8.5$, reagent concentration $0.05 \%$ ) lead to maximum and reproducible results also with the flow injection sample processing. The signal (peak height) used for flow injection determination of copper is also influenced by flow rate, sample volume, mixing coil and reaction coil lengths and organic to aqueous phase flow rate ratio. The above parameters were optimized to give maximum and reproducible results.

Flow rate. The effect of the total flow rate on the peak height and the linearity of the calibration graph is shown in Fig. 2. A flow rate of $2.0 \mathrm{ml} / \mathrm{min}$ was selected, which gave maximum and constant peak height. An increase in the flow rate led to an increase in sampling rate, but at the same time the base line

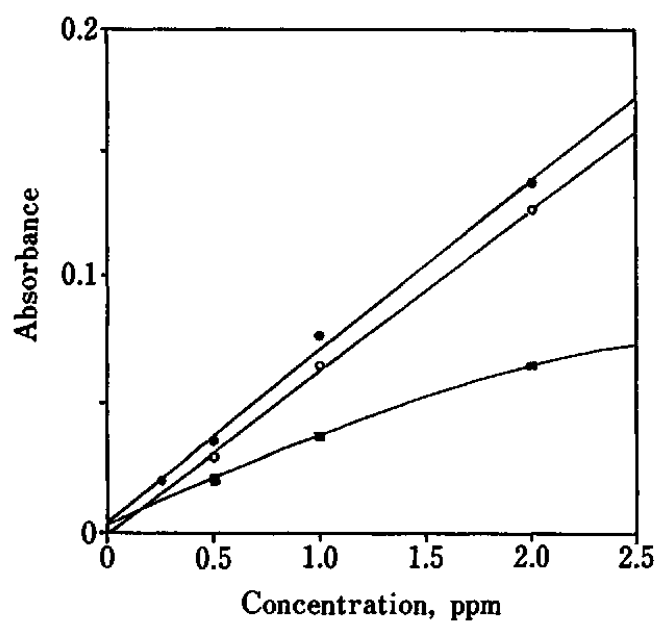

Fig. 2 Effect of total flow rate on the peak height. (O) 0.9,(O) 2.0 , (口) $5.0 \mathrm{ml} / \mathrm{min}$. $\mathrm{L}_{1}, 50 \mathrm{~cm} ; \mathrm{L}_{2}, 400 \mathrm{~cm}$; sample volume, $300 \mu 1$. 
became less stable and the peak height decreased due to incomplete reaction. The latter drawback can be overcome by using a longer reaction coil, but this leads to a larger dispersion of the signal. Moreover, the phase separation efficiency is negatively affected and some aqueous phase may enter the detector cell causing high noise, making the determination impossible. On the other hand, lower flow rate leads to the lower sampling frequency. Maximum aqueous to organic phase flow rate ratio is advantageous due to a large preconcentration factor and resulting high sensitivity. The ratio equal to 3 was found to be optimum. A higher ratio negatively affected the reproducibility of the signal and the efficiency of the separation of the phases.

Sample volume. The effect of the sample volume on the peak height and the linearity of the calibration graph was examined by injecting the varying volume (50 to $500 \mu \mathrm{l}$ ) of $0.25-2.0 \mathrm{ppm}$ copper standard solutions. Figure 3 shows that the sensitivity increases almost linearly with the increasing sample volume. Furthermore, the linearity of the calibration graph which is the prerequisite of the successful determination was lost when samples larger than $300 \mu \mathrm{l}$ were injected. Furthermore, the injection of large volumes resulted in a decrease in sampling rate. A $300 \mu$ l sample volume was chosen as a compromise, leading to a sampling rate of $64 \mathrm{~h}^{-1}$ instead of the rate of 80 attained when $200 \mu$ l samples were injected.

Coil length. The effect of the lengths of the mixing coil and the reaction coil on the peak height was examined. Long coils lead to a more stable base line and better reproducibility but at the same time to a larger dispersion of the injected sample and thus to a decrease in the peak height. A hundred and four hundreds centimeters mixing and reaction coils, respectively, were selected as a compromise.

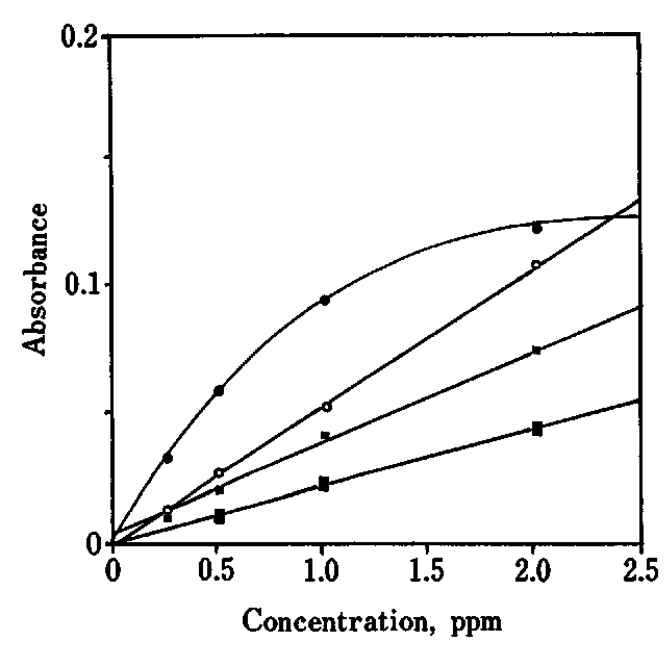

Fig. 3 Effect of sample volume on the peak height. (D) 100 , (四) $200,(O) 300,(O) 500 \mu \mathrm{l} . \mathrm{L}_{1}, 50 \mathrm{~cm} ; \mathrm{L}_{2}, 400 \mathrm{~cm}$; total flow rate, $2.0 \mathrm{ml} / \mathrm{min}$.
Choice of the analytical system

The most commonly used dithiocarbamate in the spectrophotometric analysis is Na-DDTC. The determination of copper with it is relatively sensitive $\left(\varepsilon=1.5 \times 10^{4}\right)$ but suffers from many interferences. ${ }^{1}$ The main interfering metals are $\mathrm{Fe}, \mathrm{Bi}, \mathrm{Mn}, \mathrm{Ni}, \mathrm{Co}, \mathrm{Cr}$ and Mo, which form colored extractable complexes. The selectivity of the method can be increased by masking, varying of $N, N$-substituents in the dithiocarbamic acid or using its salts. These possibilities are discussed below in detail.

Effect of masking agents. In the conventional (nonflow) method, the selectivity is considerably enhanced by the use of EDTA in tartrate or citrate medium. Figure 4 shows the influence of these masking agents on the signal from $\mathrm{Cu}$ and interfering elements when the flow injection sample processing was used. Citrate masks the interfering elements apart from $\mathrm{Ni}$ but at the same time reduces the $\mathrm{Cu}$ signal by about $80 \%$. The use of EDTA in tartrate medium does not completely remove the interferences from most metals (except from $\mathrm{Cd}, \mathrm{Zn}$ and $\mathrm{Cr}$ ), reducing simultaneously the signal from copper by $50 \%$. The reason for this is probably that the rate of the reaction of $\mathrm{Na}-\mathrm{DDTC}$ with $\mathrm{Fe}, \mathrm{Mn}$ and $\mathrm{Co}$ is slower than that of $\mathrm{Cu}$. In consequence masking with EDTA, although successful in conventional procedures, is unsuitable when flow injection sample processing is applied.

Effect of $N, N$-substituents. Some derivatives of dithiocarbamic acid (as Na-salts) were examined as potentially advantageous reagents for the flow injection extraction spectrophotometric determination of copper. The results are shown in Fig. 5. The sensitivity of $N, N$ substituted derivatives of dithiocarbamic acid in conventional extraction procedures is practically equal. However, when flow injection sample processing was applied, the signal from copper pyrrolidinedithiocarba-

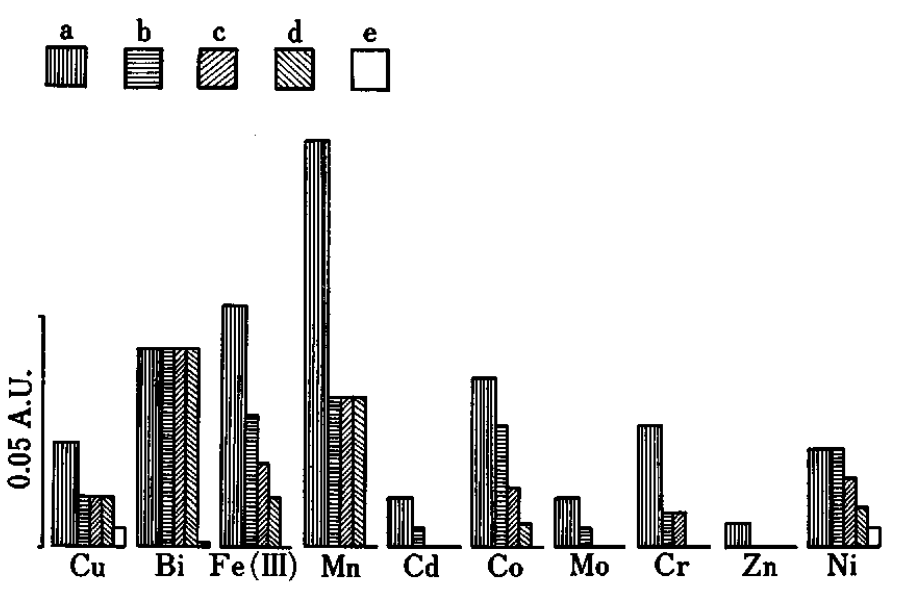

Fig. 4 Effect of masking agents on the flow-injection signals from $\mathrm{Cu}$ and interfering cations (2 ppm of $\mathrm{Cu}, 10 \mathrm{ppm}$ of interfering cations) in optimized conditions. a, without masking; b, $5 \%$ tartarate $+0.1 \%$ EDTA; c, $5 \%$ tartarate $+0.2 \%$ EDTA; d, $10 \%$ tartarate $+0.1 \%$ EDTA; e, $10 \%$ citrate. 


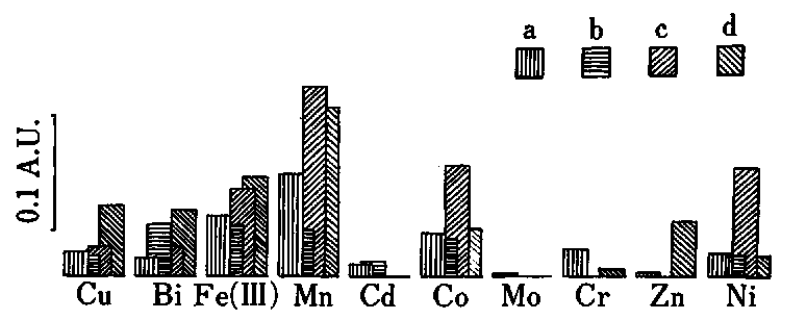

Fig. 5 Effect of the $N, N$-substituents in sodium dithiocarbamate on the flow-injection signals from $2 \mathrm{ppm}$ of $\mathrm{Cu}$ and $10 \mathrm{ppm}$ of interfering cations in optimized conditions. a, diethyl-; b, dimethyl-; c, diphenyl-; d, pyrrolidinedithiocarbamate.

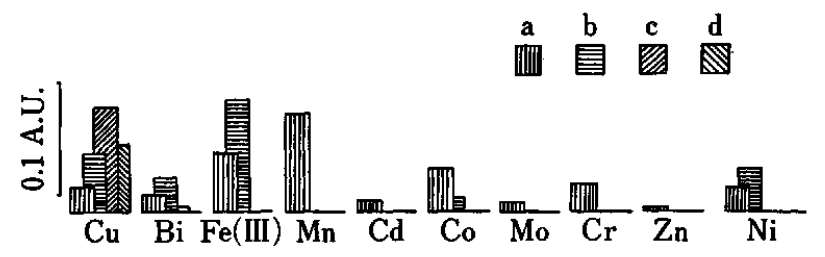

Fig. 6 Effect of the cation in diethyldithiocarbamic acid salts on the flow-injection signals from $2 \mathrm{ppm}$ of $\mathrm{Cu}$ and $10 \mathrm{ppm}$ interfering cations in optimized conditions. $\mathrm{a}, \mathrm{Na} ; \mathrm{b}, \mathrm{Zn} ; \mathrm{c}$, $\mathrm{Pb} ; \mathrm{d}, \mathrm{Ag}$.

mate (PyDTC) is thrice as high as that from other derivatives (probably for kinetic reasons). A considerable increase in signals from all the interferents is also observed. In the case of DMDTC and DPDTC the signals from $\mathrm{Cu}$ remain the same, whereas those from interfering species are higher. The most promising were found to be DDTC and PyDTC.

Effect of the cation in dithiocarbamic acid salts. The stability of metal diethyldithiocarbamates decreases in the series: ${ }^{19}$

\section{$\mathrm{Ag}>\mathrm{Cu}>\mathrm{Ni}>\mathrm{Bi}>\mathrm{Pb}>\mathrm{Cd}>\mathrm{Co}>\mathrm{Zn}>\mathrm{Fe}(\mathrm{III})$.}

Hence, it can be expected that when salts of a comparable stability with Cu-DDTC are used as reagents, the interferences with metals right from copper should vanish. However, the experiments with flow injection sample processing only partially supported this allegation. The effect on the signal from copper when the $\mathrm{Ag}, \mathrm{Pb}, \mathrm{Zn}$ and $\mathrm{Na}$ salts were used is shown in Fig. 6. It can be seen that only the interferences with $\mathrm{Bi}$, $\mathrm{Co}$ and $\mathrm{Fe}(\mathrm{III})$ remain when the $\mathrm{Zn}$-DDTC was used and only Bi interferes (its interference being, however, reduced by a half) when the $\mathrm{Pb}$ DDTC was used. The reduction of interferences with the use of Ag-DDTC is complete but, as this reagent is yellow, the noise level rises and the stability of the base line is negatively affected (the same with Ni-DDTC). The most suitable was found to be Pb-DDTC which allows for very selective and sensitive determination of

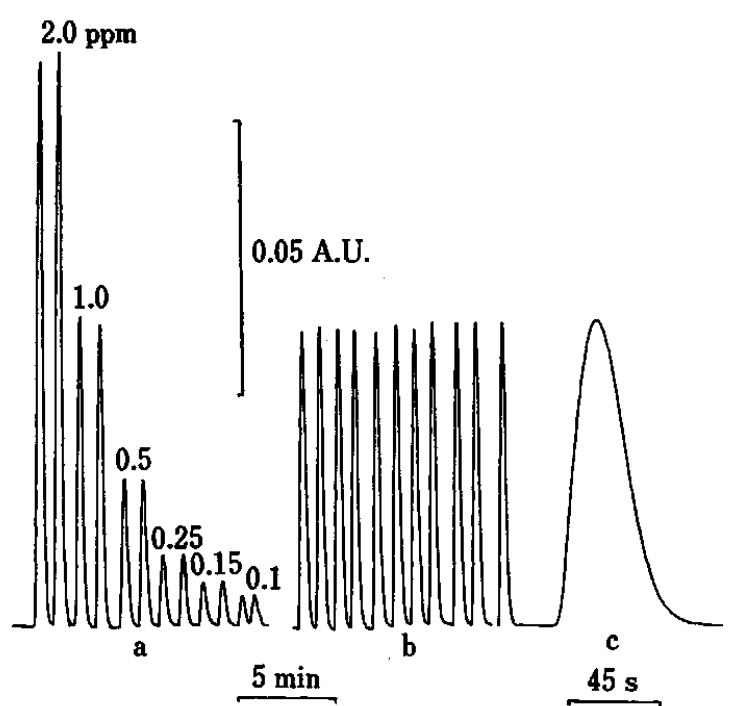

Fig. 7 Flow injection signals obtained in the extractionphotometric determination of copper in optimized conditions.

Table 1 Results of copper determination in the synthetic samples containing $\mathrm{Fe}(\mathrm{III}), \mathrm{Co}, \mathrm{Cd}, \mathrm{Cr}, \mathrm{Zn}, \mathrm{Mo}, \mathrm{Mn}$ and $\mathrm{Ni}$ (100 ppm of each element)

\begin{tabular}{|c|c|c|c|c|c|}
\hline \multirow{2}{*}{$\begin{array}{c}\text { Sample } \\
\text { No. }\end{array}$} & \multicolumn{2}{|c|}{$\mathrm{Cu}, \mathrm{ppm}$} & \multicolumn{2}{|c|}{$S^{a}$} & \multirow{2}{*}{$\begin{array}{c}\text { Confidence } \\
\text { limits } \\
(\alpha=0.95)\end{array}$} \\
\hline & Added & Found & ppm & $\%$ & \\
\hline 1 & 0. & & 0.007 & 2.7 & $0.26 \pm 0.01$ \\
\hline 2 & 0.50 & 0.49 & 0.011 & 2.3 & $0.49 \pm 0.01$ \\
\hline 3 & 1.00 & 0.97 & 0.020 & 2.1 & $0.97 \pm 0.02$ \\
\hline 4 & 1.50 & 1.53 & 0.026 & 1.7 & $1.53 \pm 0.03$ \\
\hline
\end{tabular}

a. Standard deviation; estimated for 10 injections.

copper.

\section{Determination of copper}

Calibration graph. The calibration graph was prepared by the recommended procedure using the flow system shown in Fig. 1. Typical signals showing the good precision of measurements and the negligible carry-over are shown in Fig. 7(a,b). It can be calculated from Fig. 7 (c) that a throughput of 64 samples per hour can be attained. Ten standard solutions containing $1 \mathrm{ppm}$ of $\mathrm{Cu}$ were injected and analyzed by the proposed method. The precision was $2.2 \%$. The calibration graph is linear (correlation coefficient 0.9987 ) up to $2 \mathrm{ppm}$ of copper. The detection limit (triple noise level) is as low as $0.04 \mathrm{ppm}$ of $\mathrm{Cu}$.

Analysis of synthetic samples. To show the accuracy of the method, synthetic samples containing copper at four concentration levels and $\mathrm{Fe}(\mathrm{III}), \mathrm{Mn}, \mathrm{Cd}, \mathrm{Co}, \mathrm{Mo}$, $\mathrm{Cr}, \mathrm{Zn}$ and $\mathrm{Ni}$ (100 ppm of each element) were analyzed. The results given in Table 1 show good precision and accuracy of the method developed.

Analysis of real samples. The method developed was 
Table 2 Results of copper determination in real samples

\begin{tabular}{|c|c|c|c|c|c|c|}
\hline \multirow{2}{*}{ Sample } & \multicolumn{2}{|c|}{$\mathrm{Cu}, \mathrm{ppm}$} & \multirow{2}{*}{ Recovery, \% } & \multicolumn{2}{|c|}{ Standard deviation ${ }^{\mathrm{a}}$, } & \multirow{2}{*}{$\begin{array}{l}\text { Confidence limits } \\
\qquad(\alpha=0.95)\end{array}$} \\
\hline & Added & Found & & ppm & $\%$ & \\
\hline \multirow[t]{2}{*}{ Carrot $^{b}$} & - & 2.49 & - & 0.072 & 2.9 & $2.49 \pm 0.07$ \\
\hline & 0.50 & 3.12 & 104.3 & 0.084 & 2.7 & $3.12 \pm 0.08$ \\
\hline \multirow[t]{2}{*}{ Spinach $^{b}$} & - & 3.15 & - & 0.101 & 3.2 & $3.15 \pm 0.10$ \\
\hline & 0.50 & 3.62 & 99.2 & 0.109 & 3.0 & $3.62 \pm 0.10$ \\
\hline \multirow[t]{3}{*}{ River water } & - & 0.07 & - & 0.002 & 3.2 & $0.07 \pm 0.002$ \\
\hline & 0.20 & 0.26 & 96.3 & 0.007 & 2.7 & $0.26 \pm 0.01$ \\
\hline & 0.30 & 0.37 & 100.0 & 0.011 & 2.9 & $0.37 \pm 0.01$ \\
\hline
\end{tabular}

a. Estimated for 10 injections. b. Diluted three times before analysis because of high $\mathrm{Cu}$ content.

applied to the analysis of river water and some biological meterials. The results are shown in Table 2 . The recovery of the standards added to the sample matrix was very good. The accuracy of the method was verified by the determination of copper in the Bowen's Kale certified reference material. The result obtained $4.75 \pm 0.22 \mathrm{ppm}$ was in a good agreement with the certified value $4.9 \pm 0.42 \mathrm{ppm}$.

In the flow-injection spectrophotometric methods of copper determination reported hitherto, solvent extraction was not used; hence in the majority of them the detection limits obtained are substantially worse than in the method developed. A comparable detectablity was reached only for the determination with bathocuproinedisulfonic acid after on-line reduction of $\mathrm{Cu}$ (II) and with commercially unavailable reagents. A better detection limit was obtained by Leach et al. ${ }^{13}$ who used serial differential detection. Its worth noting, however, that the above methods were not applied to real sample analysis because of poor selectivity.

This study has demonstrated a possibility of applying the solvent extraction flow-injection sample processing for spectrophotometric determination of copper. The method is simple in instrumental approach and its precision and accuracy are satisfactory for the application to river waters and plant materials analysis. The extraction of copper with a zinc diethyldithiocarbamate solution was used successfully for illustrating the concept of continuous copper preconcentration in a closed-loop system.

\section{References}

1. Z. Marczenko, "Separation and Spectrophotometric Deter- mination of Elememts", Horwood, Chichester, 1986.

2. E. B. Sandell and H. Onishi, "Photometric Determination of Traces of Metals", Wiley, New York, 1978.

3. A. S. Inglis and P. W. Nicholis, Mikrochim. Acta [Wien], 1975 II, 553.

4. W. R. Wolf and K. K. Stewart, Anal. Chem., 51, 1201 (1979).

5. W. E. van den Linden and R. Oostervink, Anal. Chim. Acta, 127, 39 (1981).

6. J. F. van Staden and C. C. P. Wagener, Anal. Chim. Acta, 179, 217 (1987).

7. M. Yamada and S. Suzuki, Anal. Chim. Acta, 193, 337 (1987).

8. M. Yamada and S. Suzuki, Chem. Lett., 11, 1748 (1982).

9. A. Faizullah and A. Townshend, Anal. Chim. Acta, 172, 291 (1985).

10. M. Tachibana, T. Inamura, M. Saito and K. Kina, Bunseki Kagaku, 32, 776 (1983).

11. M. Wada, T. Ishizuki and G. Nakagawa, Mikrochim. Acta [Wien], 1983 II, 235.

12. R. M. Smith and T. G. Hurdley, Anal. Chim. Acta, 166, 271 (1984).

13. R. A. Leach, J. Ruzicka and J. M. Harris, Anal. Chem., 55, 1669 (1983).

14. R. M. Ramasamy and H. A. Mottola, Anal. Chim. Acta, 127, 39 (1981).

15. S. Kawamoto, T. Katsumata, M. Iwatsuki and T. Fukasawa, Analyst [London], 113, 1827 (1988).

16. B. Karlberg, Anal. Chim. Acta, 214, 29 (1988).

17. R. H. Atallah, J. Ruzicka and G. D. Christian, Anal. Chem., 59, 2909 (1987).

18. K. Backstrom, L. G. Danielsson and L. Nord, Anal. Chim. Acta, 169, 43 (1985).

19. A. Wyttenbach and S. Bajo, Anal. Chem., 47, 1813 (1975). 